\title{
Trace Ammonia Analysis by Direct Gas Chromatography
}

\author{
Harvey S. Bellamy
}

QUALITY DIVISION

APRIL - JUNE 1975

Normal Process Development

Endeavor No. 223

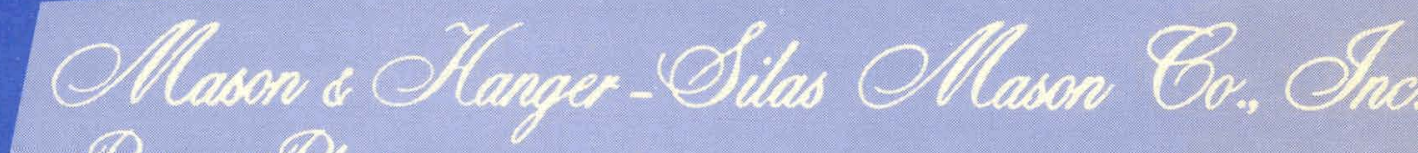

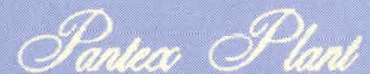 \\ P. $0.80 \times 647$ \\ AMARILO, T3XS 79177 \\ $806-385-1581$ \\ eperated for the \\ ENERGY RESEARCH AND DEVELOPMENT AOMINISTRATION under \\ O S. COVEANMENT ConTract DA. 11 -173 AMC $4 B 7(A)$}




\section{DISCLAIMER}

This report was prepared as an account of work sponsored by an agency of the United States Government. Neither the United States Government nor any agency Thereof, nor any of their employees, makes any warranty, express or implied, or assumes any legal liability or responsibility for the accuracy, completeness, or usefulness of any information, apparatus, product, or process disclosed, or represents that its use would not infringe privately owned rights. Reference herein to any specific commercial product, process, or service by trade name, trademark, manufacturer, or otherwise does not necessarily constitute or imply its endorsement, recommendation, or favoring by the United States Government or any agency thereof. The views and opinions of authors expressed herein do not necessarily state or reflect those of the United States Government or any agency thereof. 


\section{DISCLAIMER}

Portions of this document may be illegible in electronic image products. Images are produced from the best available original document. 


\section{NOTICE}

This report was prepared as an account of work sponsored by the United States Government. Neither the United States nor the United States Energy Research and Development Administration, nor their employees, nor any of their contractors, subcontractors, or their employees, makes any warranty, express or implied, or assumes any legal liability or responsibility for the accuracy, completeness or usefulness of any information, apparatus, product or process disclosed, or represents that its use would not infringe privately-owned rights. 


\section{Trace Ammonia Analysis by Direct Gas Chromatography}

Harvey S. Bellamy.

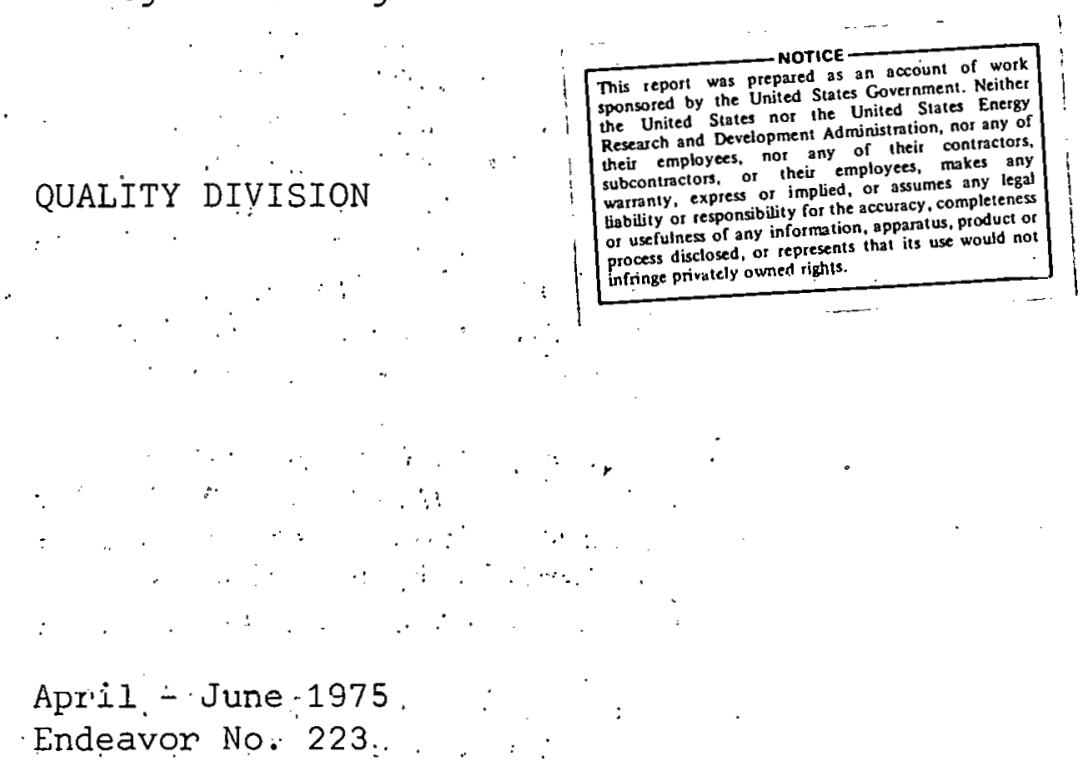

$k-1$

DISTRIBUTION OF THIS DOCUMENT IS UNLIMIILD 


\section{ABSTRACT}

A method was sought by which a gas sample could be analyzed directly for trace quantities of ammonia without the need for cryogenic fractionation or other means of ammonia concentration. Such a method has been developed: Gas chromatography of an as-received sample using a Porapak $N$ column and an ultrasonic detector is capable of detecting ammonia down to $150 \mathrm{ppm}$ with an accuracy of $\pm 10 \%$. The method is quite rapid and would lend itself well to analysis of a large number of samples in a short length of time.

\section{EXPERIMENTAL}

In October, 1973, we were informed that certain organic parts in the W69 outgased ammonia as a by-product of the post cure reaction. We later received funds as part of Normal Process Development Endeavor 223 and a request to seek out a satisfactory method for determining ammonia level in weapons atmosphere samples and the level of ammonia in w69 atmospheres in particular. At that time no one was certain what concentrations would be encountered, nor what levels were acceptable. It was only known that levels high enough to cause great discomfort were encountered upon disassembly. The-olfactory threshold for ammonia detection is considered to be $20 \mathrm{ppm}(1)$. The hope was to be able to detect and quantize levels of ammonia between $20 \mathrm{ppm}$ and several percent within 5 to $25 \mathrm{ppm}$. This was to prove overly optimistic.

The usual mode of analysis of gas samples in this laboratory is direct gas chromatography of a portion of the sample using a sampling manifold and fixed volume sample loop. This method is used due to the low concentrations of the materials to be detected, and the fact that most samples received have a total pressure below atmospheric at our altitude.

Because of the low levels of ammonia that we expected to encounter, we chose this method, mainly due to the short analysis time this would require compared with cryogenic fractionation. Too many samples were anticipated for cryogenic fractionation to be practical.

All sorts of exotic materials and combinations for separation of amines and related ammonia compounds are found in the literature. One combination was tetrahydroxyethylethylenediamine (THEED) and tetraethylenepentamine (TEP) on a finely divided fluorocarbon support. A batch of this was duly prepared, i.e., 5 weight percent of a $3: 1$ mixture of THEED and TEP on Tee Six support. The resultant packing was so flocculant that it had to be packed into a $6.4 \mathrm{~mm}$ OD column $(5.02 \mathrm{~g} / \mathrm{m})$. Bleed was so bad after 12 hours at $115 \mathrm{C}$ that a technician informed this author that the chromatograph was burning some insulation somewhere. Exotic mixtures from the literature were thus abandoned.

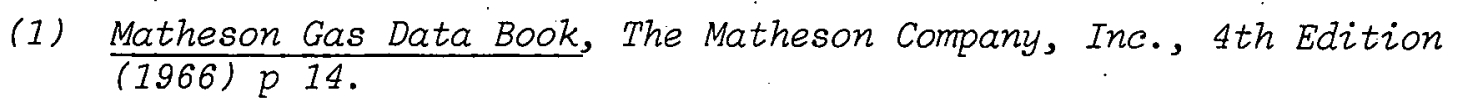


Numerous standard packings were tried. The preliminary work was done with Porapak $Q$ and a thermal conductivity detector. Results were poor. In addition, weapon samples would contain essentially air concentrations of oxygen, so the TCD filaments would eventually burn out. Based on this, it was decided to try a Tracor ultrasonic detector(2) with an air carrier. We have three Tracor MT-150G chromatographs with ultrasonic detectors (USD) which this laboratory uses for trace analysis of argon and oxygen (helium carrier) and helium, neon, and hydrogen (argon carrier). With a 2 me sample loop and a sample pressure of 0.88 atmosphere $\left(8.9 \times 10^{5} \mathrm{P}\right)$ the $0.5 \mathrm{ppm}$ of hydrogen in air is readily detected by this instrument.

With the high sensitivity of the USD and the elimination of air conponent peaks by use of an air carrier, it was expected that an ammonia analysis technique would be quickly developed. Work was begun using the vacant side of the dual USD used for $\mathrm{Ar}$ and $\mathrm{O}_{2}$ analysis. A column packed with Pennwalt Amine 223 on firebrick was installed and gave what appeared to be moderate sensitivity to $\mathrm{NH}_{3}$. However, this material did not separate ammonia, hydogren and methane, all expected weapon atmosphere components, in a satisfactory manner. Porapak $N$ was next tried and seemed to give equal sensitivity as well as separate the above three gases.

At this point a new detector was installed in our backup/developmental MT-150G, so operations were moved to this instrument. Sensitivity seemed to diminish appreciably. The instrument checked out satisfactorily though, so the earlier results were taken to be flukes. Part of the problem seemed to be adsorption of ammonia by the walls of the stainless steel lines used in the manifold and chromatograph. This had been seen on the other instrument as well, so tubing with a Teflon $($ liner was used for all possible connecting lines and a large (10 ml) sample loop was installed. Teflon lined unions were prepared in-house, but the coating bled badly and these were replaced by standard swagelok unions. These lines improved the reproducibility of runs, though about four runs were required to saturate the system so that fairly constant sensitivities could be obtained and reproducibilities could be low. A rest period of greater than about one-half hour required resaturation of the system with several shots of standard or one of pure ammonia (see Fig. 1). Note the short turn around time.

Separation of ammonia and other components were great enough on a $1 \mathrm{~m}$ column that a $0.3 \mathrm{~m}$ column was prepared and installed. This still produced sufficient separation at $175 \mathrm{C}$ and considerably increased peak sharpness and thus sensitivity. Tailing was not nearly so great as on the $1 \mathrm{~m}$ column. It was noted that upon sample injection, several positive and negative peaks occurred during the first thirty seconds of the chromatogram. Switching to pure nitrogen carrier eliminated the later peaks in this series with no other obvious changes. Sensitivity was not noticeably changed. The reason for this was not clear, but it was decided to continue with nitrogen carrier since baseline noise level was also reduced. 
At this point we were still unable to detect the $187 \mathrm{ppm}$ ammonia in air level in a purchased standard mixture. The noise level at lower attenuations was high, and peak sharpness was insufficient to make the ammonia peak stand out. One percent ammonia in nitrogen standards were used. From the sensitivities obtained and the noise level encountered, $500 \mathrm{ppm}$ was estimated to be the minimum detectable level of ammonia.

Work was next directed at increasing sensitivity by various means. On a Tracor MT-150G, as modified for our analyses, flow is controllable by a flow controller up stream of the column and a back pressure regulator down stream of the detector. Flow was $175 \mathrm{ml} / \mathrm{min}$ with a head pressure of $100 \mathrm{psig}\left(6.9 \times 10^{5} \mathrm{~Pa}\right)$ preset in order to get the sharpest possible peaks, with a back pressure of $90 \mathrm{psig}\left(6.2 \times 10^{5} \mathrm{~Pa}\right)$. Flow proved to be at near optimum level, so a switch was made to an argon carrier. The literature(2) indicates that sensitivity with this detector is generally proportional to the difference in molecular weights of the carrier and the component being eluted. Thus, argon was expected to give twice the sensitivity obtained with nitrogen.

This was tested by switching cärrier gases initially and then varying operating parameters, all with disappointing results. Argon carrier eventualiy gave higher sensitivities than nitrogen carrier, but in some cases it gave less sensitivity than nitrogen carrier. The noise level was not improved. This portion of the work was carried out after a number of weapons samples had been checked for ammonia, all. with negative results. Even one known to contain ammonia gave negative results, which prompted the search for higher sensitivity. We were thus left with the operating parameters shown in Table I. The only practical means of increasing the sensitivity would be to raise the column temperature all the way to the manufacturer's $190 \mathrm{C}$ recommended maximum and increase the volume of the already large sample loop. Loop volume increases alone cannot go very far, however, before depletion of the $75 \mathrm{~m}$ initial sample results. The maximum pressure one could expect would be about 450 torr in a $10 \mathrm{me}$ loop versus 420 torr for a 20 me loop. Doubling the loop size would not quite double the response and would further deplete the sample for any rerun that might be required.

Thus, the minimum detectable level of ammonia by direct gas chromatography of a gas sample is about $150 \mathrm{ppm}$. This is an upsetting conclusion, considering that we had gone into this research expecting an order of magnitude better detectability. However, a method exists which gives fairly good results at the 5 to $100 \mathrm{ppm}$ levels that was of much interest. In the late stages of the project, Roy Merryman of LASL suggested that we try a Drager $(3)$ tube. This is a clear glass tube having a linear graduated scale on the outside and filled with a colored mixture held in with porous plugs in the tube ends. The tube is attached to a small hand pump which draws a fixed volume of gas through the tube

(2) H.W. Grice and D. J. David, Jourmal of Chromatographic Science, Vol. 7 (Apriz 1969) pp 239-247.

(3) A. G. Drä̈er, West Germany, Lux Sci. Inst. Corp., Box 272, Canal Street Station, New York, New York 10013. 


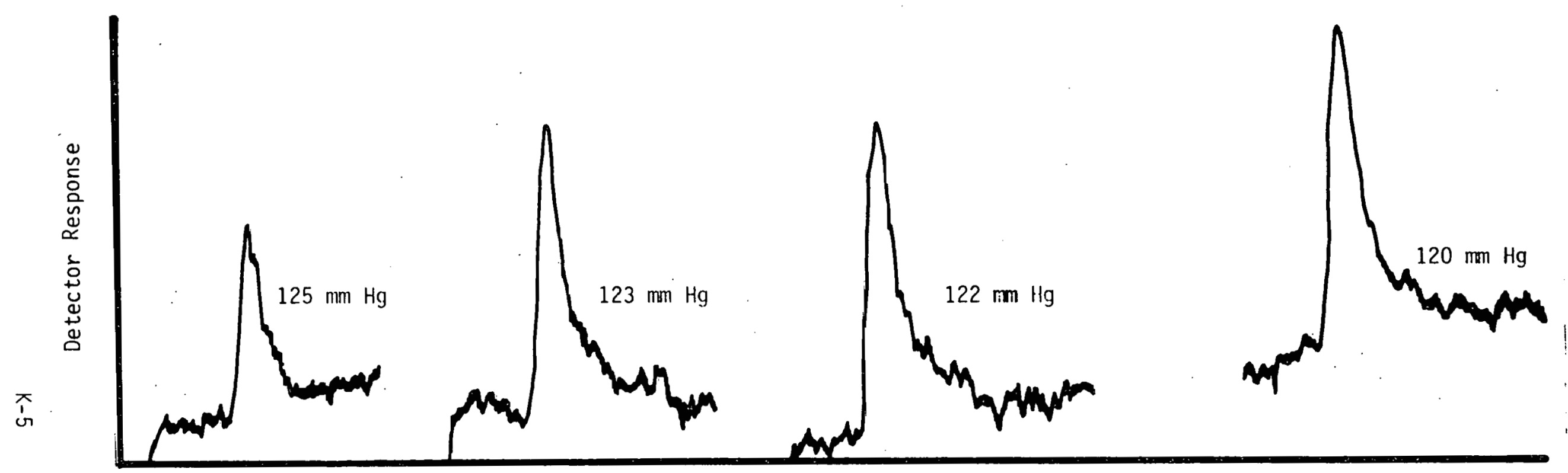

Fig. 1. Four Injections of $0.88 \%$ Ammonia Standard Ranging from $125 \mathrm{~mm} \mathrm{Hg}$ Total Pressure on the Left to 120 on the Right (Chart Speed, $0.5 \mathrm{in} / \mathrm{min}$; attenuation, X4). 
Table I. Operating Parameters

\section{Carrier}

Column Temperature (C)

Sample Loop (m\&)

Column Length $(\mathrm{cm})$

Column Packing

Carrier Flow (cc/min)

Sensitivity $(\mu \mathrm{V} / \mathrm{mm} \mathrm{Hg} / \mathrm{ppm})$

Noise Level at $X 1$ Attenuation $(\mu V)$

Minimum Detectable $\mathrm{NH}_{3}$ Level (ppm at $500 \mathrm{~mm} \mathrm{Hg}$ ) Sample Pressure
Argon

175

10

100

Porapak N

190

$2.04 \times 10^{-3}$

77

150
134

Nitrogen

175

10

30

Porapak N

175

$1.05 \times 10^{-3}$

510 
for each pump stroke made. A chart allows one to arrive at a concentration for the gas in question based on the sensitivity of the material inside the tube, the length of the material which changes color, and the volume of gas pumped through the tube.

Three surveillance units were checked by this method and gave values of $30 \mathrm{ppm}, 70 \mathrm{ppm}$ and $85 \mathrm{ppm}$ ammonia. These units' atmospheres were also sampled at the source of ammonia and gave values by the Dräger tube of from $200 \mathrm{ppm}$ to $450 \mathrm{ppm}$. Since samples taken for Gas Analys is Laboratory analysis are always taken through a Schrader valve in the area where the low ammonia contents were found, it is obvious that the minimum level detectable by gas chromatography is too high to be of much value.

\section{CONCLUSIONS}

Direct gas chromatographic analys is of a gas sample for trace quantities of ammonia is feasible down to a level of about $150 \mathrm{ppm}$. A large sample volume, compared to those normally used in this laboratory, would be required and precision would be much worse than the $5 \%$ that we expect on over half of our chromatographic analyses. Speed of analys is would be especially high. However, samples would have to be run in batches because of ammonia adsorption in connecting lines if the analysis were to be time efficient. This same adsorption probably limits absolute accuracy to about $10 \%$.

\section{A.CKNOWLEDGEMENTS}

Special thanks go to Carl 01 son and Michael Payne for their assistance in the NPD endeavor. They performed some of the column preparation and all the weapons sample analyses covered here. 